\title{
NİF OLYMPOS DAĞI ANTİK DÖNEM INNSANLARININ SAĞLIK SORUNLARI
}

\author{
Alper Yener YAVUZ ${ }^{1}$ \\ Ayla SEVIM EROL ${ }^{2}$ \\ İbrahim Semih ONUR ${ }^{3}$
}

Atıf/@: Yavuz, A.Y., Sevim Erol, A., ve Onur, İ., S. (2018). Nif olympos dağı antik dönem insanlarının sağlık sorunları. Hitit Üniversitesi Sosyal Bilimler Enstitüsü Dergisi, 11(3), 2345-2355. doi: 10.17218/hititsosbil.462460

Özet: Nif Olympos Dağı Kazı ve Araştırma projesi, konum olarak İzmir ili, Kemalpaşa, Torbalı ve Buca ilçelerinin ortak sınırlarındadır. İzmir (Smyrna) Körfezi’nin doğusunda yer alır. Kuzeyinde Kemalpaşa (Nif / Kryos Çayı) Ovası ve Manisa (Sipylos) Dağı; doğusunda Smyrna-Sardeis yolunu Küçük Menderes (Kaystros) Vadisi'ne bağlayan Karabel Geçidi; güneyinde Torbalı Ovası yer alır (Tulunay 2006). Proje kapsamında 4 farklı alanda kazı çalışmaları yapılmaktadır. Bu 4 farklı kazı alanının dönemleri de birbirinden farklıdır. Dönem gözetmeksizin yapılan kazı çalışmalarından ele geçen iskeletler değerlendirildiğinde toplamda 97 birey tespit edilmiştir. Ayrıca her bir alanda kendi içerisinde de demografi çalışması yapılmıştır. Tespit edilen bireylerin 50'si erkek, 17 tanesi kadın, 10 tanesi çocuk, 4 tanesi bebektir. 16 bireyin ise cinsiyeti belirlenememiştir. Nif Olympos Dağı Kazı ve Araştırma Projesi iskeletlerinde patolojik olarak da birçok bulguya rastlanılmıştır. Özellikle bu bulgular içinde trepanasyonun olması oldukça önemlidir. Nif Olympos Dağı Kazı ve Araştırma Projesi'nde ele geçen trepanasyon örneği hem teknik olarak hem de uygulama bölgesi olarak Anadolu örneklerinden oldukça farklıdır.

Anahtar Kelimeler: Nif Dağı, Patoloji, Trepanasyon

\section{Health Problems of the Mount Nif People in Ancient Period}

Citation/@: Yavuz, A.Y., Sevim Erol, A., and Onur, İ.S. (2018). Health problems of the mount nif people in ancient period. Hitit University Journal of Social Sciences Institute, 11(3), 2345-2355. doi: $10.17218 /$ hititsosbil.462460

Abstract: Mount Nif (Olympos) Research and Excavation Project is in the common boundaries of İzmir province, Kemalpaşa, Torbalı and Buca districts. It is located in the east of Izmir (Smyrna) bay. In the north there is Kemalpaşa (Nif / Kryos Brook) plain and Manisa (Sipylos) Mountain; in the east there is the Karabel Passage connecting Smyrna-Sardis road to the Küçük Menderes (Kaystros) valley; in the south there is Baghdad plain (Tulunay 2006). Excavations have been carried out in four different areas. The periods of these 4 different excavation areas are also different from one another. When the skeletons collected from the excavations without considering the period were evaluated, a total of 97 individuals were identified. In addition, demographic studies were conducted in each area. Of the identified individuals, 50 were male, 17 were female, 10 were child and 4 were infants. The sex of 16 individuals was not determined. There also found many pathological findings in Mount Nif (Olympos) Excavation and Research Project skeletons. It is especially important to have

Makale Geliș Tarihi: 1.9 .2018

Makale Kabul Tarihi: 3.10.2018

1 Sorumlu Yazar Arş. Gör, Burdur Mehmet Akif Ersoy Üniversitesi, Fen Edebiyat Fakültesi, Antropoloji Bölümü, Burdur/Türkiye.

2 Prof. Dr., Ankara Üniversitesi, Dil ve Tarih Coğrafya Fakültesi, Antropoloji Bölümü, Sihhıye- Ankara/Türkiye.

${ }_{3}^{3}$ Bursa Uludağ Üniversitesi, Sosyal Bilimler Enstitüsü Arkeoloji Anabilim Dal,, Yüksek Lisans Öğrencisi, Bursa/Türkiye. 
trepanation in these findings. The sample of trepanation found in the Mount Nif (Olympos) Excavation and Research Project is quite different from the Anatolian samples both technically and as a region of application.

Keywords: Mount Nif, Pathology, Trepanation

\section{GİRIŞ}

Nif (Olympos) Dağı Kazı ve Araştırma Projesi kapsamında günümüze dek dört farklı alanda çalışma yapılmıştır. Bu alanlardan Ballıcaoluk, Karamattepe, Başpınar mevkilerinde sistemli kazı çalışmaları yapılmış olup, Dağkızılca'da ise daha çok tahrip edilmiş mezarlar üzerine çalışmalar gerçekleştirilmiştir.

Ballıcaoluk: İzmir ili Nif (Olympos) Dağı projesi, 2004 yılında yüzey araştırmasıyla Prof. Dr.Elif Tül TULUNAY başkanlığında bir ekiple başlamış olup, Ballıcaoluk 2007 yılında tescillenerek sistemli bilimsel çalışmalar başlatılan bir arkeolojik yerleşim yeridir (Tulunay, 2006, 2007, 2008, 2009). Nif (Olympos) Dağ1, İzmir (Smyrna) Körfezi'nin hemen doğusunda, hem deniz hem de iç kısımla bağlantılı olup, verimli topraklar, madenler ve çok sayıda su kaynağına sahip antik dönemdeki önemli yerleşim yerlerine yakın ve verimli arazi yapısı nedeniyle doğal korunaklı, yerleşime uygun bir bölge olduğu belirtilmiştir (Tulunay, 2006, 2007, 2008, 2009 ve Yavuz, 2010). Nif (Olympos) Dağ1 İzmir'in doğusunda, Kemalpaşa (Nymphaion), Buca ve Torbalı ilçelerinin ortak sınırında yer almaktadır. Kuzeyinde Kemalpaşa Ovası, doğusunda Smyrna-Sardeis yolunu Kaystros (Küçük Menderes) Vadisi'ne bağlayan Karabel Geçidi, güneyinde Torbalı Ovası vardır. Karabel, Tmolos (Boz Dağlar) ve Nif Dağı arasında önemli bir dağ geçididir (Türkmen 2011). Bu bölge bugün Kemalpaşa (eski Nymphaion), Buca, Bornova ve Torbalı ilçelerinin sınırları içinde bulunmaktadır (Tulunay 2006). Nif Dağı Araştırma ve Kazı Projesi kapsamında Ballıcaoluk ile birlikte çalışılan Karamattepe, Dağkızılca ve Başpınar mevkilerinde MÖ 8. yy'dan MS 13. yy'a kadar yerleşim katmanları tespit edilmiştir (Türkmen, 2011).

Yolların gözlenmesine uygun yerdeki Ballıcaoluk, Hellenistik Dönem'de tahkimli bir kale işlevinde kullanılmış ve buradaki yerleşimim, hem Geometrik/Arkaik hem de Hellenistik Dönem'de Karamattepe yerleşim yeriyle bağlantılı olduğu belirtilmiştir (Türkmen, 2011). Ballicaoluk'ta yüzeyde ve kazılarda bulunan keramik buluntular, MÖ 7. yy'dan Bizans Dönemi'ne kadar uzanan yerleşim evrelerinin varlığı açıklar niteliktedir. Roma ve Bizans Dönemi'ne ait az sayıda da olsa keramik buluntularına rastlanmıştır.

Karamattepe kazı alanının kuzey batısında yer alan Ballıcaoluk yerlessimi, kuzeyi Hacıefendi Deresi, güneyi Narlı Dere ile çevrili kayalık bir tepe üzerinde konumlanmıştır (Meriç, 1988). Yörede Ballıcaoluk için "Kız Kalesi” ismi kullanılmaktadır (Doğer - Gezgin, 1998). Üç yanı sarp kayalık olan tepeye, yalnızca Karamattepe tarafındaki doğu yamacından ulaşılmaktadır (Türkmen 2011). Ballıcaoluk'taki surlarda doğal dik yamaçlar ve kayalıkların da sur sisteminin bir parçası olduğu belirtilmektedir. Sur içinde yer alan mimari kalıntı, duvar örgüsü ve planının Bizans Dönemi'ne ait özellikleri yansıttığ1 belirtilmektedir. (Türkmen, 2011). Ballıcaoluk'tan ayrıca demir ve bronz ok uçları da ele geçmiştir. Bunun yanı sıra Ballıcaoluk'la birlikte aynı projede bulunan Başpınar mevkiinde Bizans yapı kompleksi ele geçmiştir (Baykan, 2012). Bizans sanatı uzmanlarının görüşüne göre yapı, M.S 13.yy’a tarihlendirilmektedir. Yapının birden çok evreye sahip olduğu kazılar sonucu ortaya konmuştur (Tulunay 2010). 
Ballıcaolukla birlikte aynı projede yer alan Karamattepe: Ballıcaoluk Kalesi'nin doğu yamacındaki Atizi mevki ve bunun devamı olarak modern yolun karşısındaki Karamattepe oldukça büyük bir alandır (Yavuz 2010). Bölge genel olarak ormanlık alan olup çam ağaçlarıyla kaplı ama kazının yapıldığı yer ormanın tam başladığı vişne ağaçlarıyla kaplı bir tarladır. Karamattepe mevkiinde M.Ö.8.yüzyılın son çeyreğinde M.Ö. 6.yüzyıl ortalarına dek keramik ve küçük buluntularla tarihlenen, genelde dikdörtgen mekanlara ait ana kayaç üzerinde yer alan bir-iki taş sırası korunagelmiş temel ve duvar kalıntılarına sahip, bir Geometrik-Arkaik Dönem yerleşimidir (Tulunay 2010). Arkaik dönem yerleşimi ve Hellenistik Dönem nekropolünün kullanım zaman ve tarihleri kazı sırasında elde edilen keramik, metal ve cam buluntularıyla da desteklenmiştir Yavuz 2010). Karamattepe'nin Arkaik Dönem'de bir mekânlar barındıran bir yerleşim yeri olduğu daha sonradan aynı alanın M.Ö 4.yüzyılın son çeyreğinde bir nekropol olarak kullanım gördüğü saptanmıştır (Tulunay 2008).

\section{MATERYAL METOT}

Çalışmamızın materyalini Nif Dağı Araştırma ve Kazı Projesi kapsamında yer alan Ballıcaoluk arkeolojik alanından çıkarılan bir grup insan iskeleti ve hayvan kemikleri oluşturmuştur. Bu çalışmada incelenen iskeletler iyi korunmuş biçimde çıkarılmıştır. İskeletler Mehmet Akif Ersoy Üniversitesi Fen-Edebiyat Fakültesi Antropoloji Bölümü Laboratuvarı'nda temizlendikten sonra, mezar numaralarına göre birey ayırımı yapılarak onarılmıştır. Bu çalışmaların ardından tüm bireylere ait iskeletlerden biyolojik yaş, cinsiyet ve morfolojik tanımlamalar yapıldıktan sonra Ballıcaoluk insanlarının biyolojik profili oluşturulmaya çalışılmıştır. Detaylı demografik analiz yapılacak sayıda olmayan Ballıcaoluk iskeletleri mezar numaralarına göre ayrılmıştır, bireyler tek tek detaylı incelenmiştir.

İskeletlerin cinsiyetleri, boyut ve morfolojik kriterleri, öncelikle pelvis (kalça kemikleri) ile kafa iskeletindeki farklılıklardan yararlanılarak belirlenmiştir. Yaş tayini yaparken dikkat edilmesi gereken husus: bireyin bebek (0-2,5 yaş), çocuk (2,5-18 yaş), genç erişkin (18-35 yaş), orta erişkin (35-45 ve 45 yaş üstü ileri erişkin) ya da erişkin olduğunun belirlenmesidir. Bireylerin biyolojik yaşlarının tahmininde ise; bebek, çocuk ve erişkin olarak sınıflandırıldıktan sonra, bebek ve çocuk yaşları: Dişlerin tomurcuklanması ve diş sürüm zamanı, kemikleşme merkezleri ve kemik birleşme yaşları dikkate alınırken, genç erişkinlerde epifiz kaynaşmaları, daimi üçüncü azı dişlerin gelişimleri ve basilar kaynaşmadan yararlanılmıştır. Erişkinlerin yaşları tahminlerinde ise, iskeletin mevcut olan bölümlerine göre: kafa dikişlerinin kaynaşması, kalça kemiğinin ön birleşme yüzeyinin görünümü, köprücük kemiğindeki değişimler, kol ve bacak kemiklerindeki kemik yoğunluklarının durumu, diş aşınmaları ve diş kayıpları ile tüm kemiklerdeki yıpranmalar dikkate alınarak bireylerin yaşları tahmin edilmeye çalışılmıştır. Paleodemografik çalışmalarda Ubelaker, Acsadi-Nemeskeri, morfolojik değerlendirmede kullanılan biyometrik ölçülerin alınmasında ve bunlardan hesaplanan endis siniflandirmasinda, Olivier, Bass ve Martin - Saller'dan yararlanılmıştır. Boy uzunluğunun hesaplamasında Pearson(1899), Trotter-Gleser(1952) ve Sağır'ın (2000) boy regrasyon formülleri kullanılmıştır. Paleopatolojik bulguların saptanmasında Ortner-Putschar'dan yararlanılarak, kemikler makroskobik olarak incelenmiştir. 


\section{BULGULAR}

Çalışmamızın materyalini Nif Dağı Araştırma ve Kazı Projesi kapsamında ele geçen bir grup insan iskeleti oluşturmaktır. Dönem ve alan ayırmaksızın yapılan demografik çalışmalar sonucunda toplam 97 birey tespit edilmiştir. Tespit edilen bireylerin 50 si erkek, 17 tanesi kadın, 10 tanesi çocuk, 4 tanesi bebektir. 16 bireyin ise cinsiyeti belirlenememiştir (Tablo 1). Topluluğu oluşturan bireylerin yaş dağılımına bakıldığında ise toplam 67 bireyin yaş grubu tespit edilebilmiştir. Bunlardan 4 genç erişkin bireyin 2 tanesi erkek 2 tanesi de kadın bireylerdir. Orta erişkin bireylerin 28 tanesi erkek 10 tanesi kadındır. İleri erişkin bireylerin ise 20 tanesi erkek 5 tanesi kadındır (Grafik 1). Kazı alanlarından ele geçen iskeletler ayrı ayrı değerlendirildiğinde ise;

3.1.Ballicaoluk: Toplam 15 birey belirlenmiş olup bu bireylerin, 10' u erkek 3 tanesi kadındır. Ayrıca 2 tane de çocuk bireye ait iskeletler tespit edilmiştir. Yaş dağılımlarına bakıldığında ise 10 erkek 3 kadın birey bulunmuştur. 10 erkek bireyin 7 tanesi orta erişkin 3 tanesi ileri erişkindir. Kadın bireylerin ise 2 tanesi orta erişkin 1 tanesi ileri erişkindir (Grafik 2).

3.2.Başpınar: Başpınar kazı alanından toplamda 53 bireye ait iskelet bulunmuştur. Bu bireylerin 3 tanesi bebek, 4 tanesi çocuk, 6 tanesi kadın, 30 tanesi erkek, olarak tespit edilmiştir. Kazılar sonucu ele geçen iskeletlerin 10 tanesinin ise cinsiyeti belirlenememiştir. Erkek bireylerin 2 tanesi genç erişkin, 16 tanesi orta erişkin, 12 tanesi ileri erişkindir. Kadın bireylerin 2 tanesi orta erişkin, 4 tanesi ileri erişkindir(Grafik 3).

3.3.Karamattepe: Yapılan kazılar sonucunda Karamattepe kazı alanından toplam 29 birey tespit edilmiştir. Bu bireylerin 6 tanesinin cinsiyeti belirlenememiştir. Cinsiyeti belirlenebilen bireylerin 8 tanesi kadın, 10 tanesi erkek, 4 tanesi çocuk, 1 tanesi bebektir. Tespit edilen 10 erkek bireyden 1 tanesi genç erişkin 7 tanesi orta erişkin 2 tanesi ileri erişkindir. Kadın bireylerin ise 7 tanesi orta erişkin 1 tanesi ileri erişkindir (Grafik 4).

Nif Dağı kazı alanlarını erken dönem (Karamattepe), geç dönem (Başpınar, Ballıcaoluk) olarak ayırıp iskeletleri bu şekilde değerlendirdiğimizde, geç dönem kazı alanlarından ele geçen iskeletlerin say1s1 68'dir. Bu 68 bireyden 10 tanesinin yaş1 ve cinsiyeti belirlenememiştir. Yaşı ve cinsiyeti belirlenebilen bireyler içinde, 9 kadın, 40 erkek, 6 çocuk, 3 bebek vardır (Tablo 2). Kadın bireylerden 4 tanesi orta erişkin 5 tanesi ileri erişkindir. Erkek bireylerden ise 2 tanesi genç erişkin, 23 tanesi orta erişkin, 15 tanesi ileri erişkin olarak belirlenmiştir.

\section{PATOLOJİK BULGULAR}

Nif dağı araştırma ve kazı projesi kapsamında 3 farklı kazı alanından ele geçen iskeletler üzerinde yapılan patolojik incelemeler sonucunda farklı hastalıklar tespit edilmiştir. Bu hastalıklar dönemlere göre ayrı ayrı değerlendirilmeye çalışılmıştır (Grafik 5).

Osteofit: Osteofitler biçimleri ve büyüklükleri değişkenlik gösteren eklem yüzeylerinin kenarında kendini gösteren yeni kemik oluşumlarıdır. Omurga ve vücudun bütün eklemlerinde görülebilirler. (Steinbock, 1976). Toplam 36 bireyde osteofit tespit edilmiştir. Erken dönem iskeletlerinde 14 bireyde Geç dönem iskeletlerinde ise 22 bireyde ostefit oluşumlar gözlemlenmiştir.

Schmorl nodulü: Schmorl Nodülü: Omurlar arası disk dokusunun küçük veya büyük 
bir bölümü, bazı patolojik nedenlerle yada bir travma sonucu yerinden taşabilmektedir. Schmorl nodülleri, disk materyalinin komşu omur cisimlerinin içine doğru taşması ya da fitıklaşmasıdır Roberts ve Manchester 1995). Nif toplumunda toplam 32 bireyde schmorl nodülü tespit edilmiş olup bunların 13 tanesi erken dönem toplumunda 19 tanesi ise geç dönem toplumlarında belirlenmiştir.

Osteoarthrit: Etimolojik olarak Latincede “osteo" kemik, "artrit" kemik iltihaplanmas1 anlamına gelmektedir. Doğrudan biyomekanik aşınma, fonksiyonel ve yırtılmalardan kaynaklandığı bilinmektedir. Eklem hareketleri nedeniyle oluşan bu rahatsılık dejeneratif eklem hastalığı olarak isimlendirilmektedir. Eklemleri fazla zorlayan işlerde uğraşan bireylerde en sık rastlanan eklem hastalığıdır Larsen, 1997). Toplam 15 bireyde belirlenen osteoartritin 4 tanesi erken dönem iskeletlerinde 11 tanesi geç dönem iskeletlerinde tespit edilmiştir.

Osteomiyelit: Bir mikroorganizmanın bulaşıcı ve iltihaplı süreçler ile kemik dokuda hasar yaratması sonucu ortaya çıkan ilerleyici karakterli bir hastalıktır. Enfeksiyon kemikte sadece bir bölgede sınırlı kalabileceği gibi kemik iliğine, kortekse, periosta ve daha da ilerleyerek etraftaki yumuşak dokulara kadar yayılabilmektedir (Öztuna, 2005). Geç dönem iskeletlerinden bir tanesinde osteomiyelit tespit edilmiştir.

Enfeksiyon Hastalıkları: Organizmada hastalığa yol açan bir mikrobun genel veya yerel gelişmesi, yayılması anlamına gelir. Enfeksiyon hastalıkları, hastalık yapıcı canlıların vücuda girmesinden ileri gelen ve aynı enfeksiyon zinciriyle hasta bireylerden, sağlıklı bireylere geçebilen hastalık grubudur (Kumar ve ark, 2000). Nif toplumda 3 bireyde enfeksiyona bağlı hastalıkların sebep olduğu deformasyonlara rastlanılmıştır. Bu bireylerden 2 tanesi geç dönem iskeletlerinde 1 tanesi ise erken dönem toplumunda tespit edilmiştir.

Travma: Vücudun herhangi bir bölgesinin veya tamamının bir etkiye maruz kalması sonucunda, o bölgedeki yumuşak doku ve kemik dokusunda meydana gelen yırtık, kesik, kırık veya deformasyon olaylarının tümüne travma denir (Çeker, 2014). Toplamda 8 bireyde travma tespit edilmiştir. Bu bireylerden 3 tanesi erken dönem toplumda, 5 tanesi ise geç dönem toplumlarında belirlenmiştir.

Spina Bifida: İnsanda omurgayı oluşturan kemiklerin omurgada bir yarık veya açıklık şeklinde gelişmelerini tamamlayamamasıdır. Böylece nöral tüpün açıkta kalmasıdır. Başpınar toplumunda 1 bireyde spina bifida tespit edilmiştir.

Ankilozan: Sacrailiac eklemin romatizmal hastalığını ifade etmekle birlikte, diğer omurlarda iltihapla eklemler kaynaşma gösterebilir. Hastalık gövde, sırt, boyun, kalça, kaburga ve omuzlarda ağrı ve sertliklere neden olmaktadır (Ortner ve Putschar, 1985). Karamattepe toplumunda 1 adet ankilozan tespit edilmiştir.

Anemi: Kanın oksijen taşıma kapasitesinde dolaşımdaki alyuvarların miktarının normal seviyenin altına inmesinden kaynaklanan düşüştür. Anemi kanamadan, alyuvarların hızlanmış yıkımından ya da yavaşlamış üretiminden kaynaklanır. Karamattepe toplumunda 2 bireyde anemi tespit edilmiştir.

Trepanasyon ya da baş delgi ameliyatı, yaşayan birinin ya da bir ölünün kafatasında, öngörülen bir amaç doğrultusunda belirli bir tekniğe bağlı kalarak gerçekleştirilen operasyondur. Bu operasyon sirasinda kullanilan ameliyat aleti 'trepan' adiyla bilinir (Özbek 1999). Trepanasyona farklı bölgelerde ve kültürlerde rastlanması ayrıca tarihsel 
bir geçmişinin de olması nedeniyle, aynı zamanda kültürel boyut da içermektedir. Anadolu için, hem farklı zamanlarda hem de farklı bölgelerde rastlanılan trepanasyonun bilinen en eski uygulaması yaklaşık 10.000 yıl öncesine kadar uzanmaktadir. Trepanasyon tekniklerini başlıca dört grup altında toplanmıştır.

A. Kazıma ve Kesme tekniği;

B. Oluk açarak aradaki parçayı çıkarma tekniği

C. Yuvarlak ya da oval bir plan üzerinde küçük delikler açmak ve bunları ince bir keski ile birleştirerek ortada serbest kalan parçayı çıkarma tekniği.

D. Delme Tekniği (Özbek, 1999).

Karamattepe' de bulunan bir kafatası üzerinde sol temporal bölgede trepanasyon tespit edilmiştir (Resim 1-2). Bu birey için trepanasyon işleminin "Yuvarlak ya da oval bir plan üzerinde küçük delikler açmak ve bunları ince bir keski ile birleştirerek ortada serbest kalan parçayı çıkarma tekniği ile yapıldığı düşüncesindeyiz. Trepanasyon işlemi sonrası açılan deliğin iç kısımlarına baktığımızda çok düzgün kenarlar izlenememektedir. Kemiğin iç kısımlarının yani tabula internanın tabula externaya oranla bir birine daha yakınlaşmış olduğu görülmektedir. Bu da bize işlem yapıldıktan kısa bir süre de olsa bireyin yaşadığını düşündürmektedir (Resim 3-4).

\section{SONUÇ}

$\mathrm{Bu}$ çalışmada incelenen materyal Nif (Olympos) Dağı kazı ve araştırma projesi kapsamında, 2006-2016 yıllarında gerçekleştirilen kazı çalışmalarında elde edilen 97 bireyden oluşmaktadır. Bu bireylerin 50' si erkek, 17' si kadın, 10' u çocuk 2' si bebek ve 16 ' sının cinsiyeti ve yaşı belirlenememiştir.

Nif insanlarında 8 travma olgusu tespit edilmiştir. Bu travmaların iskeletlerde görülme sıklığı, izlerin iyileşme oranına bağlı olarak Nif insanlarındaki travmaların sebebinin çarpma, düşme gibi kazalardan kaynaklı olduğu düşünülmektedir.

Popülasyonda sıklıkla karşılaşılan osteofit ve schmorl nodülleri en çok erişkin bireylerde ve erkeklerde görülmüştür. Bu patolojik bulguların sık görülmesi toplumsal cinsiyet rolleri ve aktiviteleriyle ilişkilendirilebilir.

Nif insanlarında sıklıkla karşılaşılan bir diğer patolojik olgu osteoarthritin görülme sıklı̆̆ının fazlalığıdır. İleri yaşlardaki bireylerde görülmesi bireylerin gençlik dönemindeki ağır fiziksel aktiviteler ile ilişkilendirilebilir.

Nif toplumunda belki de en dikkat çekici olgu trepanasyonlu kafatasıdır. Kökeni prehistorik dönemlere dek uzanan bu cerrahi işlemin son y1llarda Anadolu' da da birçok örneği ile karşılaşılmıştır. Fakat bu trepanasyonu farklı kılan, uygulanan bölgenin (temporal) çok yaygın olmayışıdır.

Nİf (Olympos) Dağı kazı ve araştırma projesi kapsamında önümüzdeki yıllarda yapılacak kazılar sonucunda ele geçirilecek buluntuların bölgenin kültürel geçmişi hakkında önemli bilgiler vereceği kanaatindeyiz.

\section{KAYNAKÇA}

Acsadi, G.Y. ve Nemeskeri, J. (1970). History of human life span and mortality. Budapeşte: Akademia Kiado.

Baykan, D. (2012). Allianoi tıp aletleri/surgical instruments from allianoi, studia ad 
orientem antiquum (soa) 2. Türk Eskiçağ Bilimler Enstitüsü, Ege Yayınları, İstanbul.

Bass, W.M. (1987). Human osteology: a laboratory and field manual. Colombia:Special Publication No:2 Missouri Archaeological Society.

Brothwell, D.R. (1981). Digging up bones, 3. Baskl, London: Oxford University Press.

Buıkstra, J.E. ve Ubelaker, D.H. (1994). Standards: for data collection from human skeletal remains. Arkansas Archeological Survey Research Series, No: 44.

Çeker, D., (2014). Adli antropolojide kullanılan travma analizi metodlarının antik dönem iskeletlerine uygulanabilirliği (minnetpınarı ve güllüdere antik iskeletleri üzerine yapılan bir çalışma). Yüksek Lisans Tezi, Ankara Üniversitesi Sosyal Bilimler Enstitüsü.

Doğer, E. ve Gezgin İ. (1 998 ). Arkaikveklâsikdöne m de s my $n$ na' $n \imath n d \imath$ şsa v $n$ m a s ı üz e ri n e gözlemler. II. Uluslararası İzmir Sempozyumu, İzmir: 7-30.

Ortner, J., Donald Walter G. ve Putschar, J. (1985). Identification of pathological conditions in human skeletal remains smithsonian Institution Press.

Kumar V., Cotran R.S., ve Robbıns, S.P. (2000). Temel patoloji, (Çev.Edt: U. Çevikbas) Nobel Tip Kitabevleri, İstanbul.

Larsen, C. S., (1997). Bioarchaeology, interpreting behavior from the human skeleton, : Cambridge University Pres.

Martın, R. ve Saller, K., (1957). Lehrbuch der-anthropologie, Band I, Stuttgart: Güstav Fischer Verlog.

Martın, R. ve SALLER, K. (1959). Lehrbuch der-anthropologie, Band II, Stuttgart: Güstav Fischer Verlog.

Meriç, R. (1988) Antik dönemde küçük menderes havzasının tarihsel coğrafyasına genel bir bakış. Ege Üniversitesi Coğrafya Dergisi 4: 202-212.

Olivier, G. (1969), Practical anthropology, Charles C. Thomas Publisher, Springfi eld, Illionis.

Özbek M. (1999). Çayönü'nde kafatası delgi operasyonu: in H.Ü. Edebiyat Fakültesi Dergisi (Cumhuriyetimizin 75. Y11ı Özel Say1s1), pp.109-126.

Öztuna V. (2005). Osteomyelit Patofizyolojisi ve Tedavi Prensipler. TOTB_D (Türk Ortopedi ve Travmatoloji Birligi Dernegi) Dergisi, Cilt: 4, Sayı:1-2.

Pearson, K. (1899). Mathematical contribution on the theory of evolution. on the reconstruction of the stature of prehistoric races. Philosophical Transactions of the Royal Society, London, 192: 169-224.

Roberts, C. and Manchester, K., (1995). The archaelogy of disease, second edition, Cornell University Pres, New York.

Sağır, M., (2000). Uzun kemik radyografilerinden boy formülü hesaplanması, Basılmamış Doktora Tezi, Ankara: Ankara Üniversitesi Sosyal Bilimler Enstitüsü.

Steinbock T., (1976). Paleopathologic diagnosis and 1nterpretation bone disease in ancient human populations Springfield: Charles C. Thomas Publishers.

Trotter, M. Ve G.S. Gleser, (1952). "Estimation of Stature From Long Bones of American of American Whites and and Negroes", American Journal of Physical Anthropology, 10: 463-7514.119

Tulunay E. T. (2006). Nif (Olympos) dağı araştırma projesi: 2004 yılı yüzey araştırması, AST 23, 2, 2006, s. 189 - 200.

Tulunay E. T (2007). Nif (Olympos) dağı araştırma projesi: 2005 yılı yüzey araştırması, 
AST 24, 2, 2007, s. $351-362$.

Tulunay E. T. (2008). Nif (Olympos) dağı kazı ve araştırma projesi: 2006 yılı kazısı, 29. Kazı Sonuçları Toplantısı Kocaeli 2007, 3, Ankara: 79-98.

Tulunay E. T. (2009). Nif (Olympos) dağı araştırma ve kazı projesi: 2007 yılı kazısı, KST $30,3,2009$, s. $411-426$.

Tulunay E. T. (2010). Nif (Olympos) dağı araştırma ve kazı projesi: 2008 yılı kazısı. KST XXXI/2 (2009) 387-408.

Tulunay E. T (2011). Nif (Olympos) dağı araştırma ve kazı projesi: 2009 yılı kazısı, KST $32,3,405-423$.

Türkmen, M. (2011). "Ballıcaoluk”, E. T. Tulunay (2010). Nif (Olympos) Dağı Projesi: 2009 Y111 Kaz1s1. 32. Kaz1 Sonuçları Toplantısı, İstanbul 2010, Ankara: 414-415.

Ubelaker, D.H., (1978). Human Skeletal Remains: Excavation, Analysis, Interpretation, Chicago: Smithsonian Institution, Aldire Publishering Company. WHITE, D.T., (1991), Human Osteology, U.S.A: Academic Press. Workshop of European Anthropologist, (1980). Recommandations for age and sex diagnoses of skeletons", Journal of Human Evolution, 9 (7): 518-549.

Yavuz, A.Y., (2010). Nif (Olympos) dağı araştırma ve kazı projesinden çıkarılan hayvan kemiklerinin zooarkeolojik analizi, Yüksek Lisans Tezi, Çukurova Üniversitesi Sosyal Bilimler Enstitüsü.

\section{EKLER:}

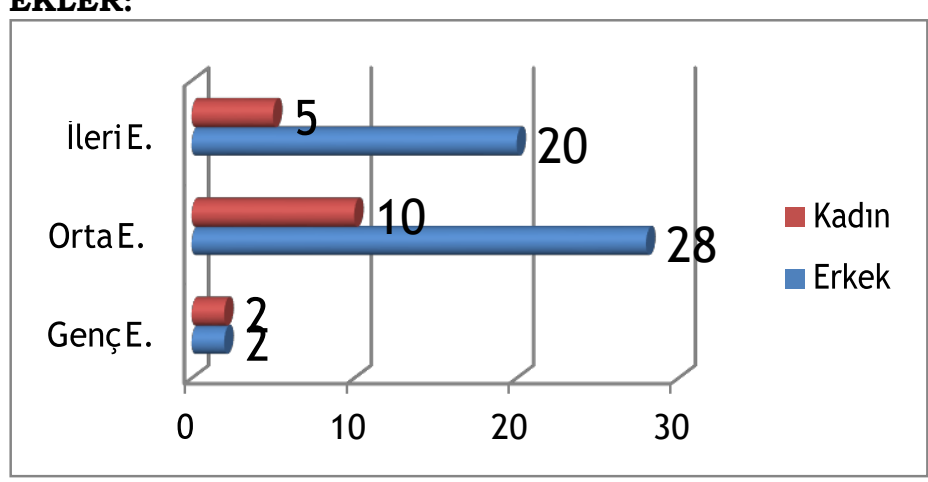

Ek- Grafik 1. Nif dağı kazısı genel yaş ve cinsiyet dağılım (2006-2016)

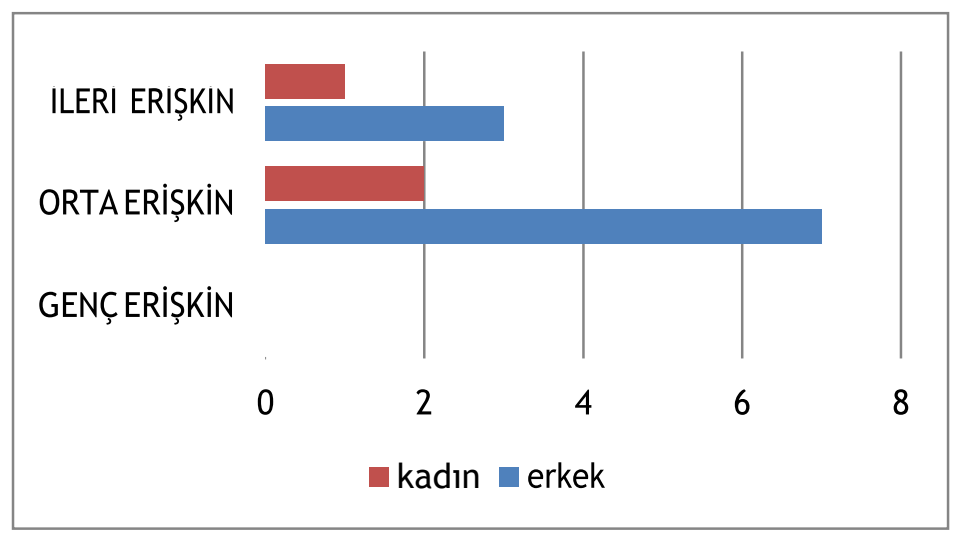

Ek- Grafik 2. Ballıcaoluk yaş ve cinsiyet dağılım (2006-2016) 


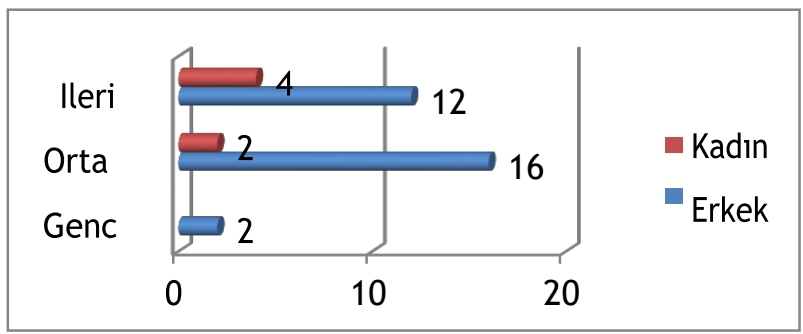

Ek- Grafik 3. Başpınar yaş ve cinsiyet dağılım (2006-2016)

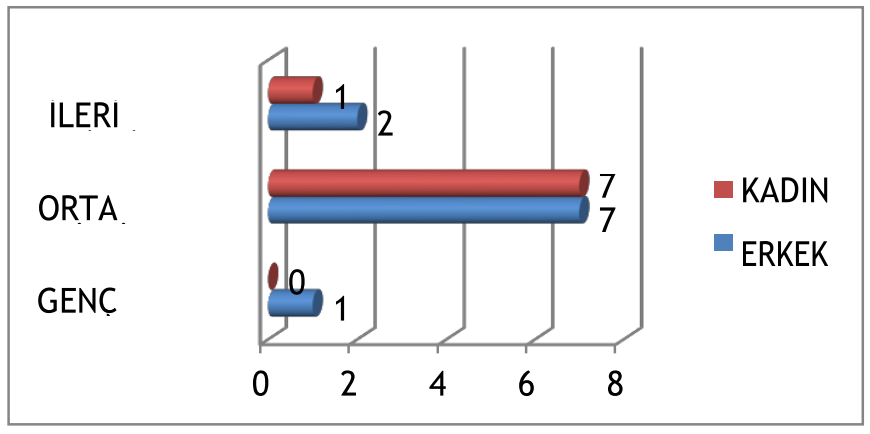

Ek- Grafik 4. Karamattepe yaş ve cinsiyet dağılım (2006-2016)

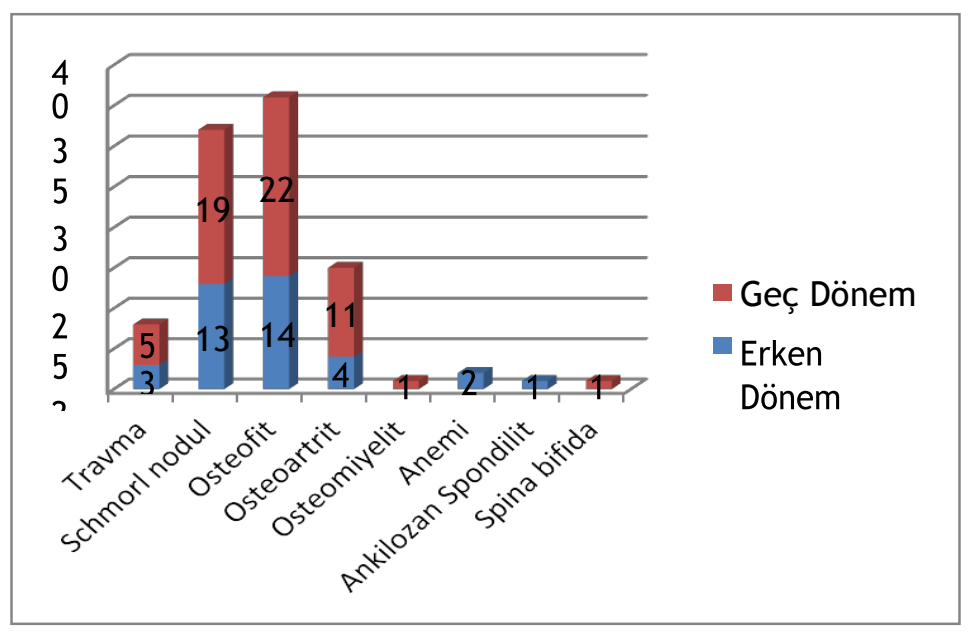

Ek- Grafik 5. Nif dağı kazısı dönemlere göre patolojik dağılım 

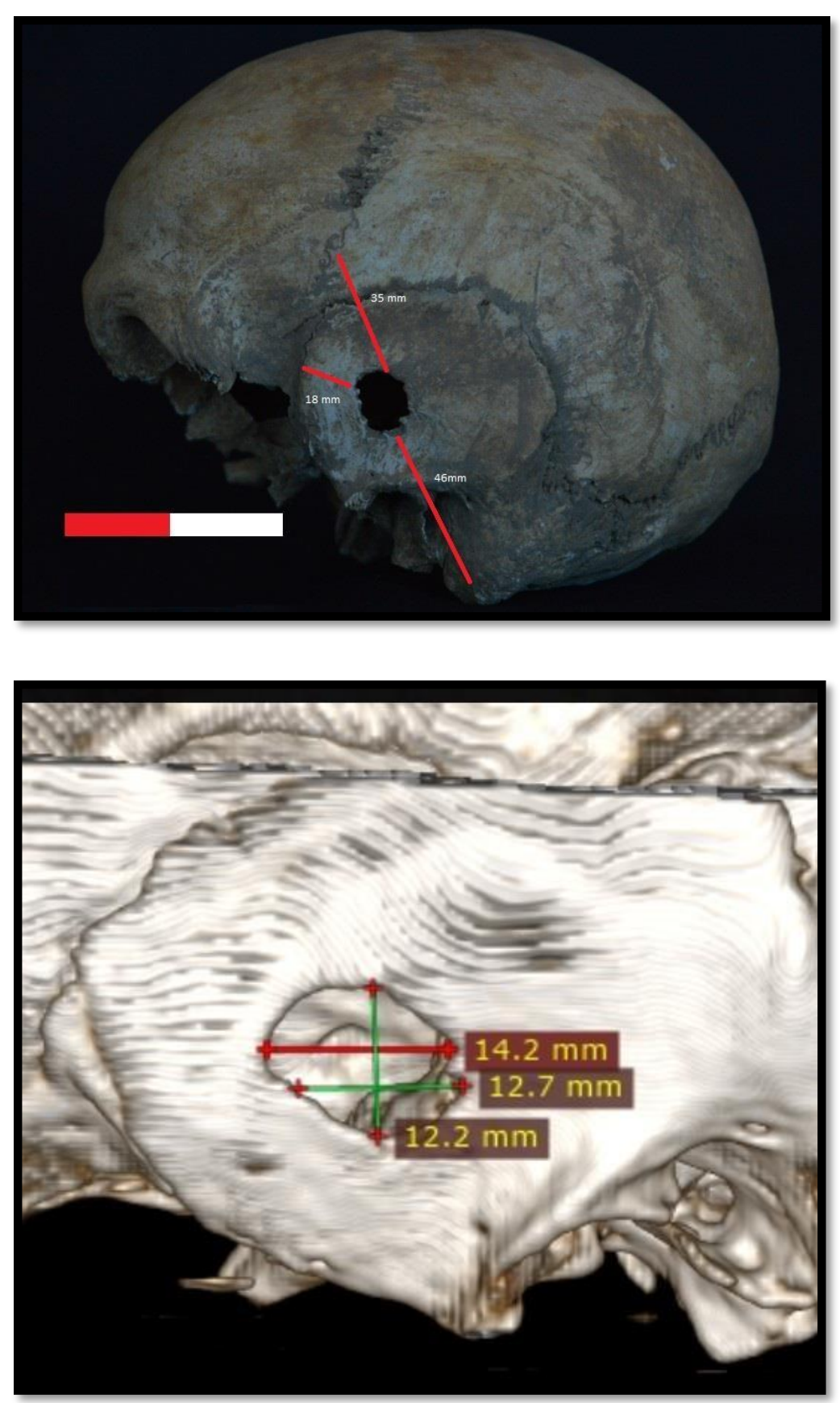

Ek- Resim 1-2: Karamattepe'de Bulunan Trepanasyona Ait Ölçümler 

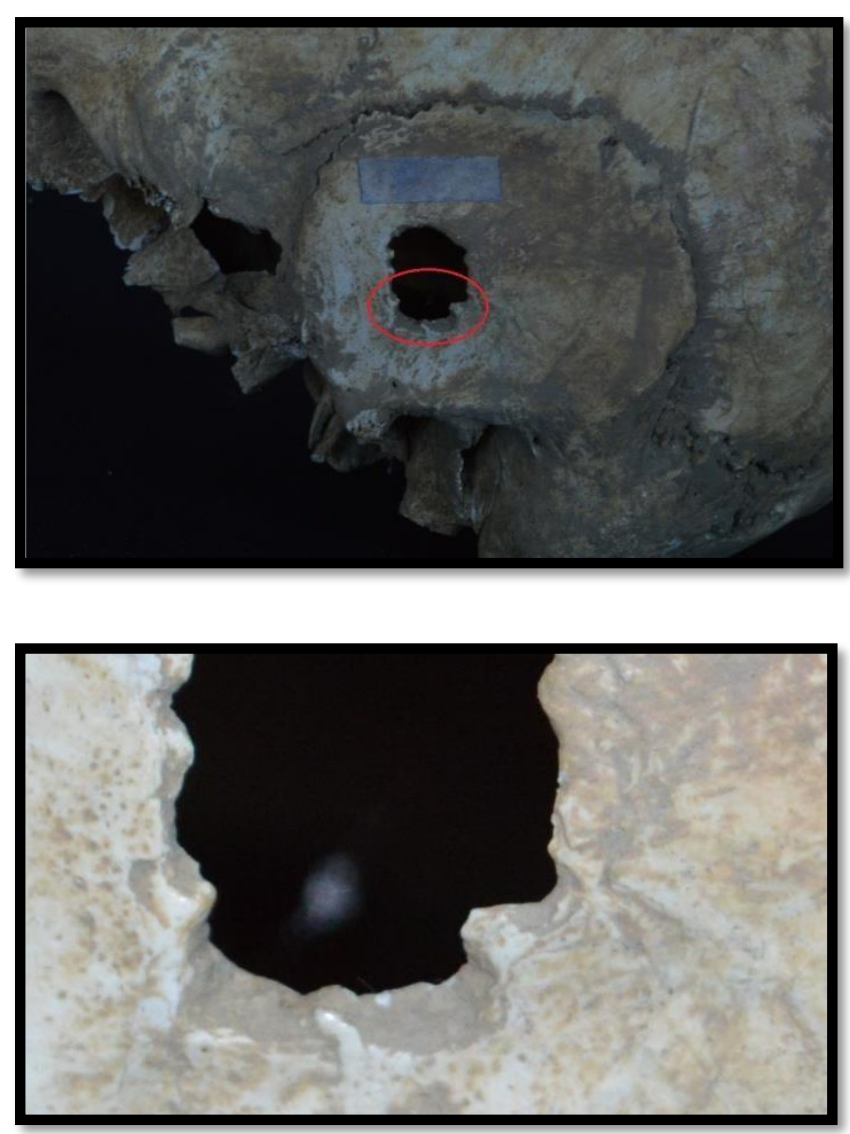

Ek- Resim 3-4. Karamattepe'de Bulunan Trepanasyon (Küçük Delikler Açarak Ortadaki Parçanın Serbest Kalması Tekniği)

Ek- Tablo 1. Nif Dağı Kazısı Genel Cinsiyet Dağılımı (2006-2016)

\begin{tabular}{rrr}
\hline & Erkek & 50 \\
\hline & Kadın & 17 \\
\hline Çocuk & 10 \\
\hline \multirow{2}{*}{ Belirlenemeyen } & 4 \\
\hline & Bebek & 16 \\
\hline
\end{tabular}

Ek- Tablo 2. Nif Dağı Kazısı Geç Dönem Cinsiyet Dağılımı (2006-2016)

\begin{tabular}{rrr}
\hline & Kadin & 9 \\
\hline & Erkek & 40 \\
\hline & Çocuk & 6 \\
\hline Belirlenemeyen & 3 \\
\hline Toplam & 10 \\
\hline
\end{tabular}

